\title{
Fast and Federal—Policies for Next-Generation Federalism in Germany
}

\author{
Hendrik Scholta, Marco Niemann, Sebastian Halsbenning, Michael Räckers, Jörg Becker \\ University of Muenster - ERCIS, Muenster, Germany \\ Email: \{hendrik.scholta|marco.niemann|sebastian.halsbenning|michael.raeckers|joerg.becker\}@ercis.uni-muenster.de
}

\begin{abstract}
Federalism and e-government are important to many countries across the globe but come up with two contradicting characteristics that are especially existent in Germany. First, citizens and businesses want to receive e-government services easily but the identification of government entities that are responsible for service delivery in federal states is difficult. Second, e-government has to react to fast developments but decision-making is distributed and rather slow in federal states. To address the area of tension between federalism and e-government, we suggest seven polices that raise internal efficiency and external simplicity of federalism in Germany. We transfer existing policies of e-government literature and practice to our research problem in the course of discussions in a research group of five people. The policies are evaluated in semi-structured interviews with eleven leaders from the German government. The evaluation reveals the appropriateness of the policies to address the issues of federalism in e-government.
\end{abstract}

\section{Introduction}

Federalism is a form of government whose main principle is to subdivide the government into several entities and balance the power between them $[12,18$, 19, 36]. In contrast to a unitary state, there is no consolidation of power at a single entity. In federalism, each government entity has different jurisdictions and delivers services to citizens and businesses according to these jurisdictions. Federalism has been widely established across the globe and countries such as the United States, Australia, Austria and Germany implement federalism in practice [9].

The emergence of e-government has led to a comprehensive transformation of governments and their service delivery [20]. In former times, government service delivery was characterized by the processing of paper documents. Nowadays, many governments offer services to their citizens and businesses through electronic channels such as websites and e-mail.

Despite their importance for governments, federalism and e-government have two contradicting characteristics. Citizens and businesses have numerous demands to e-government, which among others include quick and easy service delivery [6, 13]. However, the partitioning of responsibilities in federalism requires citizens and businesses to determine the responsible government entity, which can be a time-consuming and difficult task [16, 17]. If a government does not clearly state which government entity is responsible for delivering which service, then citizens and businesses can feel lost and their level of satisfaction with government service delivery decreases. For example, depending on their residence, citizens in Austria have to submit an application for a weapons possession card to a state entity, municipality, state police headquarters or municipal police department [10].

Additionally, whereas e-government has to react to fast developments, decision-making in federal states is slow in comparison to unitary states $[14,16,17,20]$. Rapid technological innovations such as the emergence of smartphones require a flexible adaptability of governments. Moreover, changing circumstances that necessitate appropriate technological solutions such as the refugee crisis in Europe and the resulting high number of asylum applications require fast reactions for e-government. However, a federal structure slows down a government's reaction in case many entities are involved in a specific decision-making process. For example, in Germany it took almost ten years since the emergence of the term "e-government" until the federal and state governments had agreed upon a common strategy to guide the development of e-government in the country.

Due to these two contradicting characteristics, federalism can be identified as one central problem to e-government ambitions that is especially present in Germany. From a government internal perspective, it decreases the dynamic of e-government initiatives due to slow decision-making processes. From an external perspective, federalism decreases the satisfaction of citizens and businesses with e-government services due to confusing responsibilities. 
To assist policy-makers in the German government in the resolution of the two aforementioned areas of tension between federalism and e-government, this paper addresses the following research question: How can the negative impact of federalism on e-government initiatives in Germany be reduced internally and externally? To answer this research question, we propose seven policies that address the two contradicting characteristics of federalism and egovernment and that we evaluated through semistructured interviews with experts from the German government practice. In our work, we limit egovernment to service delivery and exclude participation in democratic processes.

The remainder of this paper is structured as follows. First, we present research background in the areas of e-government and federalism. Then, we describe our research design. Afterwards, we introduce our seven policies. Subsequently, we report on the evaluation of these policies. In our discussion section, we synthesize and analyze the main insights of our work. Finally, we conclude and give an outlook on future research.

\section{Research Background}

\subsection{Federalism}

Even though federal states can be found across the world, there exists no unequivocal definition for this term [5, 18, 19]. Some scholars even suggest that federalism as a concept is still undergoing constant evolution [30]. The specific characteristic of a federal system is that power and sovereignty are shared across at least two distinct levels of government [12, 18, 19, 36]. According to common definitions such as [12, 18, $19,34,36]$, the division of power has to be arranged in a way that all levels have an equal status and are thus partly independent. Watts [34] points out that equality additionally has to be ensured through constitutional guarantees. Depending on the degree of fulfillment of the characteristics such as division of power and equality of status, a polity is a real federal state (equality between central government and states), confederation (central government is subordinate to states) or devolved government (central government is superordinate to states).

In the modern, digitized and interconnected world, federalism appears to be prospering given its characteristic of accommodating diversity and unity at the same time $[9,34]$. It is commonly agreed upon that federalism can help to account for situations where people of different ethnicity, religion or culture have to be brought together under one form of government that is non-discriminatory to all groups while maintaining a sufficient decision-making capability.

However, the federal concept has been criticized for creating severe problems when it comes to the allocation of financial resources and political power $[8$, 34]. A basic example would be a three-level federal system where the highest level (federal government) passes a law that, for instance, the lowest level (local governments) has to execute and where the question of responsibility for payment of the execution will emerge. More formalized joint decision processes - a classical mitigation strategy - cause further problems $[23,34]$. There, so-called "joint decision trap[s]" [23] can occur since every involved entity has to agree, which often leads to decisions at the lowest common denominator and, thus, suboptimal policy decisions. This cooperative approach to federalism is referred to as cooperative federalism [35] and is constitutionally applied in Germany.

\subsection{E-Government}

The digitalization of governments - often referred to as e-government-started in the mid-1990s in countries like the USA, Great Britain, Canada and Australia [20]. Focusing on the usage of information technology for business process and service delivery improvement, it was distinguished between an internal and external perspective towards e-government $[7,16$, $20,32]$. While it can be argued that given egovernment's primary goal of delivering government services of high quality, the external perspective-the relationship to citizens and businesses - should receive special attention [20], other authors claim that the bigger gains can only be realized if the internal processes are also improved [16].

While countries world-wide take up the challenge to move to the digital age by offering government services online and by digitalizing their internal processes, there have been reports since the early stages that especially federal states struggle solving these tasks $[14,20]$. The reasons that have been put forward are manifold: One of the difficulties identified in [14] is that a common digitalization project is the integration of government data into a single repository, which, for instance, in the USA - as in many other federal states-is an issue given the constitutional division of power that may get undermined if one institution is given exclusive control over the created repository. Similarly, process standardization or adjustments are hard since in a federal constitution there is no single powerful actor (neither central government nor states), which can enforce a standardization movement [14]. As a result, digitalization happens in single silos, so that, for 
instance, the central government and different states often exhibit different levels of digital capabilities [20].

Federal states and federations of states that have been associated with many of the above stated problems include the US, the EU and Germany. Especially the latter one is cited as a primary example of a federal state that struggles with digitalization. According to [16] and [17], Germany is living several federal principles such as division of power (legislation on the federal government level and execution on the local government level) and decentralization to their extremes. The result is an environment with a plethora of different variants for similar processes that is highly dismissive towards any centralization movementsand as such, it is not an environment for digitalization to flourish and bring out its advantages.

One approach to evade such issues is "government as a platform" as proposed by O'Reilly [21]. The idea is that a (federal) government only provides the digital infrastructure and potentially data, while it leaves it to other public and private bodies to fill the system with useful applications. An-admittedly non-federalexample of such a system is the highly decentralized Estonian $X$-Road [2] which serves as a data backbone for both governmental authorities and agencies as well as private institutions like banks.

\section{Research Design}

Our research design is two-fold: First, based on existing literature and discussions in a research group of five people, we developed a set of policies that address shortcomings given by federalism in terms of e-government service delivery. We transferred existing concepts in e-government literature and practice to our research problem and refined the set of policies in regular meetings until we reached a stable set of policies and all researchers agreed upon this set. On average, the members of the research group had experiences of nine years with projects in the government domain.

Second, in order to evaluate these policies against their purpose to address the issues in e-government resulting from federalism in Germany, we performed semi-structured expert interviews with practitioners from the field. We developed an interview guide that was structured into three parts. The first part consisted of questions regarding the interviewees' experiences and impressions of the interplay between federalism and e-government and problems of the federal structure in order to gain a better domain knowledge of the research problem. The second part targeted our policies and their usefulness in order to evaluate the proposed policies. In the third part, we asked the interviewees for further ideas in order to be open to policies that we had not covered initially.

We selected the interviewees in a way that all federal levels are covered almost equally. Since we address the problems of federalism and e-government on a strategic level, we selected interviewees that operate on this layer of abstraction. Our interviewees were leaders and policy-makers from all three federal levels in Germany: Four people from the local government level, three interviewees from the states level and four participants from the federal government level. The interviewees included, among others, two former and two current Chief Information Officers, a mayor and two members of administrative boards.

In April and May 2018, we conducted eleven interviews. The interviews lasted from 30:05 minutes up to $62: 54$ minutes with $48: 38$ minutes on average. Two researchers conducted each interview. We audio recorded the interviews and transcribed them afterwards. The transcripts were analyzed qualitatively; all answers of the interviewees were categorized based on a list of codes.

\section{Policies}

\subsection{External}

In this subsection, we introduce four policies that aim to make e-government services more convenient for citizens and businesses by improving the handling of government responsibilities for them. In a typical process of service delivery in e-government, an applicant has to identify the responsible government entity first and second engages with this entity by, for instance, submitting the application [37]. Whereas the first policy addresses only the first step (identification of responsibilities), the other three policies also address the second step (enactment with responsibles) in an increasingly integrated manner. The first policy facilitates the identification of responsibilities through equal structures of service descriptions. The second policy keeps the many responsibilities from the citizen and business perspective but guides the recipient from the government entity that s/he contacted first to the responsible entity. The third and fourth policies reduce the number of responsibilities.

4.1.1. Standardized Service Descriptions. The policy standardized service descriptions [1] was observed in practice and intends to harmonize the specification of government services for citizens and businesses. The basic idea is to describe services with a predefined set of attributes to obtain comparable service descriptions. Exemplary attributes can be a list of relevant forms and 
required documents, applicable fees, the responsible government entity and point of contact. In addition to a common set of attributes to describe a service, the contents of the attributes can be standardized and need only to be adapted to a government entity's individual circumstances. If services are described in the same structure and-in the case of similar services - with similar contents, then services are easier to understand and citizens and businesses can identify relevant information more easily.

The standardized service descriptions policy addresses the issue of confusing responsibilities for citizens and businesses since information on the services' responsibilities is represented equally. The reoccurrence of familiar structures and contents increases speed and comfortability for citizens and businesses. When they search for information on services from different government entities, then their efforts to identify the responsible government entity are reduced. This benefit does not only support the identification of the responsible entity but all relevant information that is necessary for service delivery from a recipient perspective such as forms and fees. This policy is also beneficial for a government internally since government entities do not need to develop service descriptions on their own but can reuse descriptions and adapt them to their cases.

4.1.2. Interconnected Portals. The policy interconnected portals results from practice [11] and intends to establish connections between the individual online portals of all government entities. A system of links between these portals guides applicants towards the responsible entity, thereby offering access to the online services of the different federal levels. Comparable to an online marketplace the functional design can be viewed as a kind of governmental marketplace because it adopts two main characteristics: First, interconnected portals have many government entities that offer their services and a huge number of potential users - analogously to high numbers of suppliers and customers in a typical digital marketplace. Second, access to the government services within the different portals is given by a unique authentication service such as single sign-on to verify the identity.

The interconnected portals policy addresses the issue of confusing responsibilities due to offering a convenient navigation for applicants. The choice of the starting point to look for online services, for instance a local or federal government portal, becomes irrelevant. From every portal onwards, users are guided through the interconnected system to the responsible authority where they can find relevant services and information. Whereas the various jurisdictions are no more obstacles, this proposal keeps the federal structure without changing the original jurisdictions. Institutions and their portals remain independent.

4.1.3. One-Stop-Shop. Whereas interconnected portals offer various starting points that guide a citizen or business to the responsible government entity, the third policy one-stop-shop [38] identified in literature offers a single point of contact to all government services in a country. Although the government guides the applicant in interconnected portals, it is the applicant's obligation to access the responsible entity and ensure that the relevant information is provided to this entity. In contrast, in a one-stop-shop the applicant consults one portal and it is the government's task to distribute the information to the right entity in the back end. Therefore, from the perspective of citizens and businesses there is only one responsible entity although the jurisdictions are preserved through separation in the back end.

The one-stop-shop policy addresses the issue of confusing responsibilities by establishing a single point of contact that is responsible for everything from the perspective of citizens and businesses. To further increase the convenience of citizens and businesses in the identification of suitable services, a government can structure the services of a one-stop shop according to life events and business situations [39]. An example of a one-stop-shop is the Estonian portal eesti.ee.

4.1.4. No-Stop-Shop. The one-stop-shop reduces the number of responsible government entities to one from a recipient perspective since there is a single point of contact. However, in an ideal scenario, a citizen or business does not even need to contact any government entity in order to receive a government service. In such a case, the recipient does not have to care about responsibilities. Therefore, in a no-stop-shop [27] the government provides services proactively so that citizens and businesses do not have to perform an action to receive a service. This policy originates from academic literature.

The no-stop-shop policy addresses the issue of confusing responsibilities due to the removal of responsibilities from a recipient perspective since the government approaches the recipient and not vice versa. In order to be able to deliver a service without an action from the recipient, a government needs to have all necessary data available and anticipate when a recipient is eligible to get a service. This requires a comprehensive data basis of high quality and, therefore, a cooperation between government entities. However, not all services can be delivered in a nostop-shop, for instance, a service like a marriage can hardly be anticipated without a citizen's hint. For 
example, Austria delivers the service family allowance - a payment to parents of children - in a nostop-shop [4].

\subsection{Internal}

Typically, organizations can be analyzed from different views such as the organizational, data and functional views $[24,25]$. Transferred to the government, the organizational view covers the structuring of a government vertically in federal levels and horizontally in functional departments, the data view deals with the information that needs to be stored to provide a service, and the functional view covers the operations that are necessary for service delivery and running a government entity. In the following, we present three policies that address these views and aim to make the internal decision-making more efficient. The first policy addresses the organizational view to bundle responsibilities for standardization at a single government entity. The second policy addresses the data view in order to consolidate government data. The third policy addresses the functional view since it centralizes operations at a single government entity.

4.2.1. Digitization Committee. In federal structures, government entities are, generally speaking, responsible for the provision of public services on their own. Therefore, the organizational structure and use of internal standards differ across institutions, leading to several constraints in inter-administrative communication, processes, and managing digitization [26]. Consequently, we propose a centralization of organizational issues in the shape of a digitization committee where we could observe some occurrences in practice. This concept comprises a central institution equipped with broad responsibilities to take the lead in the standardization and harmonization process.

The digitization committee policy addresses the issue of slow and inefficient internal decision-making due to a concentration of responsibilities for digitization. The centralized decision-making of a powerful digitization committee eliminates various individual standards by harmonizing them and giving new guidelines. This increasing governance contributes to a better inter-administrative communication. A digitization committee can be established in two different ways. On the one hand, it could be a Ministry of Digital Affairs, for instance established in Poland, and located at a single federal level. On the other hand, a committee with involvement of all federal levels can be introduced. Similarly to the already existing IT Planning Council in Germany, this way is characterized by a decision-making process, in which policy-makers of the different levels make decisions collectively.

4.2.2. Digital Identity. To ensure proper service delivery, each government entity in federal states keeps a subset of identity and personal data of citizens. The introduction of a single digital identity is meant to reduce the high degree of distribution [22, 28] and to establish a sufficiently integrated data basis to improve the provision of government services. This policy results from academic literature. A digital identity of a citizen or business integrates digitally stored attributes regarding the citizen or business such as date of birth or address. For this various approaches appear viable, ranging from the creation of a federation model [29] interlinking already existing data sources, over a single, central database towards storing all relevant information directly on the physical ID card of each citizen [28].

The digital identity policy addresses the issue of slow decision-making in federalism since it increases data consistency by establishing a single point of truth. Thereby, data can be accessed quicker since it does not need to be requested from citizen or business again, and less faulty decisions are made. Each government entity does not need to manage its data individually. Having a consolidated and integrated data basis with a unique identifier speeds up government processes through both a more efficient handling of data and the typically associated optimizations of the linked business processes [22, 28].

4.2.3. Shared-Service Center. Government entities in federal states often create different technical solutions trying to solve similar procedural problems [15]. In practice this means that since, for instance, each urban municipality or county in Germany has to offer the registration of a car, there may be almost as many different implementations requiring a department taking care of the solution. Such situations are typically regarded as inefficient, since government entities spend resources on activities such as administrating IT infrastructures that are not their core work-which is service delivery to citizens and businesses [3, 15]. To overcome such situations, the execution of a certain function can be transferred to a shared-service center that is specialized on the delivery of this function to various government entities. This concept originates from literature.

The shared-service center policy addresses the issue of slow decision-making in federalism by relieving the individual government entities of these non-core business functions, so they can focus on their core functions $[3,15]$. The extracted functions and processes are then subjected to a consolidation and 
standardization process $[3,33]$. This way costs are reduced while at the same time the degree of professionalization is increased giving all partaking government entities a higher degree of service quality-especially giving small government entities access to service degrees which would otherwise financially prohibitive [15].

\section{Evaluation}

\subsection{External}

5.1.1. Standardized Service Descriptions. The interviewees see the standardization of service descriptions as a valuable but just first step. One interviewee from the states level mentions that "I think it is a good approach [...]. It is user-oriented to transform services in really unified descriptions [...] and it also addresses the topic of identification of responsibilities by making this controllable for me as a citizen or business. But this concept is of course not enough." Another interviewee from the local government level supports this: "This is the first step. If I will not reach this step, then I will not be able to offer valuable services, which $I$ can work on in a standardized way".

Based on standardized service descriptions, further actions have to be taken such as the standardization of forms and data used for service delivery according to an interviewee from the states level: "Service descriptions are one aspect, standardized forms are another one. I have to go a step further from the service description to an action: An application that I want to send". Standardized service descriptions are seen as baseline for the further discussed policies, which can and should build on this policy.

Furthermore, an interviewee from the federal government level does not only see standardized service descriptions as valuable for the external stakeholders but also for the government internally: "I think the concept is right. I also think that we need it for government-internal purposes so that not everybody reinvents the wheel".

5.1.2. Interconnected Portals. Most of the interviewees declare the interconnected portals policy as advantageous because it is a solution to the problem of confusing responsibilities without changing them. These responsibilities are constitutionally predetermined and hardly changeable in many federal states. "If I have federalism with these three levels [...], then I have to map this structure virtually. This is the only possibility to provide citizens a portal for all requests", a person from the federal government level argues that interconnected portals avoid changes in jurisdictions.

In addition, an interviewee from the federal government level points out the clear benefits of this policy: "From the citizens' view, it is crucial that they do not have to care about the jurisdictions but can start at any portal and will be guided towards the right authority." Another interviewee from the local government level supports this opinion: "Applicants do not care about the origin of a service. [...] That is why interconnected portals are absolutely necessary in federalism to ease access and to improve quality of government services." An interviewee from the states level takes a contrary view and differs between citizens and businesses: "Interconnected portals are exaggerated from citizens' perspective. [...] The contact to the government is very rare. [...] But for businesses that are doing business nationwide interconnected portals are appropriate because this makes things easier."

Regarding future development of e-government a person from the federal government level argues: "We have to discuss the one-stop-shop in relation to interconnected portals. [...] With interconnected portals we implement the one-stop-shop policy."

5.1.3. One-Stop-Shop. Experts comment positively on the one-stop-shop. An interview from the local government level states that "I think it is reasonable, smart and useful. [...] There will be a migration from interconnected portals [...] to a one-stop-shop. [...] If we decided from the beginning that there was only a single gate for everyone in Germany, then this would challenge the individual responsibilities of the different levels".

However, not all interviewees are completely convinced by the one-stop-shop. One interviewee from the states level mentions that it "has huge advantages for users. However, for government entities it has pitfalls" since the integration of different back end systems is difficult. If there are systems with a working front end and back end, then the government should apply these systems instead of building a one-stopshop as a new front end on top: "The way is to use existing structures if they are not unreasonable and in most cases they are not unreasonable. This is more efficient and faster".

An interviewee from the states level criticizes the one-stop-shop: "I do not think it is useful. If a citizen thinks about the government, then the citizen thinks about his or her local government". Additionally, the same interviewee says that "the federal government is responsible for many laws, which are to be executed especially by local government entities. However, with a few exceptions, the federal government does not 
know how the execution reality works". Thus, the federal government would not be suitable to run a centralized platform such as a one-stop-shop without an intensive involvement of the other federal levels.

5.1.4. No-Stop-Shop. The no-stop-shop is rated as valuable policy to cope with the disadvantages of federalism for citizens and businesses. An interviewee from the federal government level states that "of course it is useful. [...] It is clear that it is very good and that citizens expect it in cases where it is possible".

An interviewee from the states level agrees that a no-stop-shop is meaningful in certain cases: "I think that there are areas such as family allowance where it is to be supportable. In the past, it rather failed since, for example, Mr. Schäuble [a former German federal minister of finance] was opposed to making the government proactive. [...] It becomes problematic if the citizen has to consent, i.e. in cases where the citizen is involved in the question what the government is allowed to do with his or her data".

According to an interviewee from the local government level, the number of potential scenarios for the no-stop-shop are low but it is also benefical for the government internally due to less applicatons that need to be processed: "There exist only a few legal situations where you can do it. I think the no-stop-shop is great since it would be little effort for us as government".

\subsection{Internal}

5.2.1. Digitization Committee. In general, the interviewees support the introduction of more common standards. More controversial in this case are the required competencies of the digitization committee as an interviewee from the states level highlights: "Such an enormous task within the government needs a powerful administration that is not just responsible for coordination. Fostering development requires jurisdictions, authority, and resources".

This leads to the question of the construction of the digitization committee, whether it is institutionalized as a ministry or more like an agency with involvement of several federal levels. A shift of jurisdictions will come along with reluctance of some affected authorities as a person from the states level mentions that "[t]he states will not accept top-down standardization made by the federal government." An interviewee from the federal government level states: "I am not a supporter of a Ministry of Digital Affairs", and argues that in this case other institutions may not feel responsible for digitization anymore. An interviewee from the local government level supports this opinion: "Digitization is a cross-sectional task", meaning that various government entities are to be involved in digitization initiatives supporting the idea of creating a new crosslevel digitization committee or extending the existing German IT Planning Council.

In contrast, an interviewee from the federal government level supports the establishment of a ministry because "[t]he current structures and the existence of the IT Planning Council did not solve the problem. We need a strong formation of objectives at the federal government level." However, the person also demands a more intensive dialogue between the federal government level and the states level.

5.2.2. Digital Identity. Interviewees rate the concept of a digital identity as a valuable tool to overcome the improvable data management in government resulting from the federal structure. One interviewee from the federal government level mentions that "of course it is helpful, if the data is stored anywhere and the citizen gives approval that his or her data can be combined with other data from other registers for certain purposes in service accounts or something similar. Thereby, one could achieve the once-only-principle".

According to the interviewees, the digital identity is valuable but they prefer a separately stored digital identity in a federation model to a digital identity on a physical ID card. An interviewee from the local government level says that "I think here in $[. .$.$] we are$ going to offer service accounts [...] in the future that allow citizens to initially on a voluntary basis enable that unlike before electronic government action can relatively easy take place here in a structured way". For the suggestion to store more digital data on an existing identity card, an expert from the local government level cautions that "on the citizen side, the citizens do not think anything of the card because they do not use it at all'.

Another topic that many of the experts refer to is data protection, which can be opposed to the integration of data in a digital identity. The sensitivity regarding this topic can be seen in comments such as the statement of another expert from the local government level who would only accept a digital identity under the condition "that the strictest data protection criteria are observed. Well, personally, I don't want me to have, let me tell you, a digital pursuit later".

5.2.3. Shared-Service Center. The interviewed experts largely agree that shared-service centers are a policy that is growing in importance given the rising degree of digitalization of the government. One interviewee from the federal government level likes "shared-service center [...], since it simply does not make sense that everyone does everything" especially 
since "no government entity can specialize in a way, that it can do everything equally well, so that it simply makes sense to have shared-service centers to handle certain things professionally".

While large municipalities may not be deeply affected by the need to rationalize, the experts clearly point out that small municipalities are often already failing to fulfill certain tasks due to a decreasing amount of personnel and an increasing complexity. One interviewee from the states level mentions that "[s]mall municipalities are often not capable to handle human resources, especially payroll accounting, on their own anymore". Another expert from the local government level adds with regard to human resources that "whether I purchase that myself, maintain [...] or if it is made available by a municipal data center, does not matter for our employees [...] they want to get their salaries".

However, with regard to federal state structures another expert from the local government level points out that "[...] in cases where I have similar legal frameworks, it is unproblematic in my view." which implies that there may exist other cases where legal aspects differ between states and/or local governments prohibiting an easy shared-service center implementation.

\section{Discussion}

The evaluation results reveal that the policies are not equally important and not suitable in all cases. Some policies are complementary whereas some are exclusive.

In the external category, the standardized service descriptions policy is the basis for other policies. A further integration-regardless of whether in the form of interconnected portals or a one-stop-shop-relies on standardized service descriptions. Federalism does not only affect the identification of responsibilities but also the design of forms. Citizens have to get familiar with different forms and businesses have to adapt their electronic interfaces to the varying data requirements. Therefore, a standardization of forms and interfaces can address further issues of federalism in German egovernment.

Interconnected portals and the one-stop-shop are exclusive policies and the decision in favor of one of these policies should depend on the number of existing e-government portals. In Germany, there are portals of several government entities; therefore, it is recommendable to reuse these implementations and establish interconnected portals. On the contrary, if there are not many existing portals, then the development of a new one-stop-shop is superior. Since citizens might have only a small number of interactions with a government each year, it can be beneficial to focus only on services for businesses. It is important to involve all federal levels in the implementation of portals or a one-stop-shop since in Germany mostly higher levels provide legal foundations for a service, but local governments have the experiences in executing this service. Some interviewees take the view that interconnected portals can simulate a onestop-shop. However, since interconnected portals forward a citizen or business to the responsible government entity, they are confronted with different responsibilities. In contrast, in a one-stop-shop there is a single responsible access point.

As an extension of interconnected portals and a one-stop-shop, the government can implement a nostop-shop for suitable services and should ask citizens and businesses whether they want to receive services proactively to account for privacy regulations.

The policies of the internal category are complementary since they address different views on an organization. Therefore, the policies can be implemented independently from each other. In order to coordinate the government's initiatives towards standardization, a digitization committee is useful. Without such a committee, it is difficult to set the standards and manage the internal organization that is necessary to deliver high quality services to citizens and businesses. Both variants-ministry or new/extended cross-level agency-have advantages and disadvantages. In any case, a digitization committee should have comprehensive authorities and act in close relation to all federal levels.

Integrating data to obtain a digital identity of citizens and businesses is beneficial to release the users from providing a piece of data more than once and increase data consistency. A federation model of data separation and integration is preferred since it represents a federal structure digitally but simultaneously allows for some centralization. Privacy is important and, therefore, the storage of a digital identity on a physical ID card can be useful since the data is stored at a place that is controlled by the citizen. In addition, an enrichment of a physical ID card with more data can increase its usefulness for users since they can transfer more data automatically when applying for a government service. This may increase the usage rate of ID cards in Germany.

Shared-service centers are useful especially for smaller government entities to release government entities from the execution of non-core business functions so they can benefit from a division of work and specialization. The execution of non-core business functions is outsourced and centralized, increasing the internal efficiency. Since they are no core functions, 
government entities are more willing to outsource such functions. Shared-service centers do not contradict a federal structure since responsibilities are kept and government entities have the possibility to insource functions again. When establishing shared-service centers, functions of those government entities should be consolidated that have similar legal frameworks since legal foundations define the functions of a government entity.

According to the German constitution, the main purpose of federalism is the balancing of power and control. Whereas in principle the policies of the external category keep the assignment of power and build only an integrated front end for citizens and businesses on top of the back end, the policies of the internal category reassign power. From a data view, data can be consolidated at a single entity. From a functional view, although the authority to decide remains the same, the operational execution of functions can be outsourced to a common institution. From an organizational view, authorities to decide can be transferred to a central entity. Thus, we expect the implementations of the external policies to be easier than the internal policies as long as there is no perceived shift of power. It is a question of how much power people are willing to release.

Despite some disadvantages of federalism on egovernment progress in Germany, we do not conclude that federalism has a negative impact in general. Federal states do not necessarily perform worse in egovernment than unitary states as indicated by the $E$ Government Development Index of the United Nations [31]. Bottlenecks for e-government also exist in unitary states.

\section{Conclusion}

In this paper, we propose seven policies to address the negative impact of federalism on e-government in Germany internally and externally.

Our paper has implications for academia and practice. Our results extend the understanding of scholars on barriers, which hinder the implementation of e-government, and enablers, which foster the development of innovative e-government solutions. We propose our policies on a high level of abstraction and scholars can extend the policies to the operational and implementation levels. Practitioners can implement our policies.

In future research, limitations of our work can be addressed. First, our research is limited to Germany although we assume that the policies are transferrable to other countries. To evaluate our policies with impressions from other countries, we would like to refine our policies based on the feedback from the participants at HICSS. Second, in order to incorporate experiences from practice, we involved government leaders with a high practical expertise in the evaluation. Nevertheless, our research would benefit from intensive case studies and feedback from other stakeholders such as citizens and businesses. This is especially necessary since our goal is to improve ease of use and efficiency although user demands may go beyond these two dimensions. Third, considering the fast transmission of information enabled by digitization, researchers can evaluate which constituents of federalism are still relevant in the digital age. Fourth, federalism mainly deals with the (re-)allocation of power. Future research could investigate how much power people are willing to release to foster digitization. Fifth, a careful evaluation of implementation challenges is needed to provide reliable recommendations which policies should be realized. Barriers such as constitutional requirements, data protection, financial capability and infrastructural needs have to be taken into consideration.

We hope that our paper creates awareness that it is necessary to address issues resulting from federalism in order to achieve a better e-government. However, we do not advocate for a removal of federalism. The balancing of power is indispensable for a stable democracy in Germany. Instead, we require a preparation of federalism for the circumstances resulting from digitization.

\section{References}

[1] Ahrend, N., P. Wolf, M. Räckers, A. Dentschev, and M. Jurisch, "Federal Information Management - Context and Effects", Proceedings of the 44. Jahrestagung der Gesellschaft für Informatik, (2014), 1499-1511.

[2] Anthes, G., "Estonia: A Model for e-Government", Communications of the ACM 58(6), 2015, pp. 18-20.

[3] Becker, J., B. Niehaves, and A. Krause, "Shared Service Center vs. Shared Service Network: A Multiple Case Study Analysis of Factors Impacting on Shared Service Configurations", Proceedings of the 8th International Conference on Electronic Government (EGOV 2009), (2009), 115-126.

[4] Bosse, J., M. Burnett, S. Møller Nielsen, C. Rongione, and H. Scholtens, European Public Sector Award 2015: The Public Sector as Partner for a Better Society, European Institute of Public Administration, Maastricht, 2015.

[5] Burgess, M., Comparative Federalism - Theory and practice, Routledge, Abingdon, UK, 2006.

[6] Carter, L., and F. Bélanger, "The utilization of egovernment services: citizen trust, innovation and acceptance factors", Information Systems Journal 15(1), 2005, pp. 5-25. [7] Casalino, N., S. Armenia, C.M. Medaglia, and S. Rori, “A new system dynamics model to improve internal and external efficiency in the paper digitization of Italian Public 
Administrations", Proceedings of the EURAM Conference, (2010).

[8] Delbruck, J., "Transnational Federalism: Problems and Prospects of Allocation Public Authority Beyond the State", Indiana Journal of Global Legal Studies 11(1), 2004, pp. 3155.

[9] Elazar, D.J., Exploring Federalism, The University of Alabama Press, Tuscaloosa, AL, USA, 1987.

[10] Federal Ministry of the Interior, "Waffenbesitzkarte Antrag",

2018.

https://www.help.gv.at/Portal.Node/hlpd/public/content/245/ Seite.2450800.html

[11] Federal Ministry of the Interior, and Building and Community, "Portalverbund digitaler Verwaltungsdienstleistungen: einfach, schnell und sicher", 2018. https://www.bmi.bund.de/DE/themen/moderneverwaltung/verwaltungsmodernisierung/portalverbund/portal verbund-artikel.html

[12] Hueglin, T.O., and A. Fenna, Comparative Federalism: A Systematic Inquiry, University of Toronto Press, Toronto, Canada, 2015.

[13] Hung, S.Y., C.M. Chang, and T.J. Yu, "Determinants of user acceptance of the e-Government services: The case of online tax filing and payment system", Government Information Quarterly 23(1), 2006, pp. 97-122.

[14] Jaeger, P.T., "Constitutional principles and Egovernment: An opinion about possible effects of federalism and the separation of powers on E-government policies", Government Information Quarterly 19(4), 2002, pp. 357368.

[15] Janssen, M., and A. Joha, "Motives for establishing shared service centers in public administrations", International Journal of Information Management 26(2), 2006, pp. 102-115.

[16] Klumpp, D., "From Websites to e-Government in Germany", Proceedings of the First International Conference on Electronic Government, (2002), 18-25.

[17] Kubicek, H., and M. Wind, "Integriertes E-Government auch im föderalen Staat? Herausforderungen auf dem Weg zu effizienten Verwaltungsverfahren", Deutsche Zeitschrift für Kommunalwissenschaften 43(2), 2004, pp. 48-63.

[18] Law, J., "Sense on Federalism", The Political Quarterly 83(3), 2012, pp. 541-550.

[19] Law, J., "How Can We Define Federalism?", Perspectives on Federalism 5(3), 2013, pp. 88-120.

[20] Lee, S.M., X. Tan, and S. Trimi, "Current practices of leading e-government countries", Communications of the ACM 48(10), 2005, pp. 99-104.

[21] O'Reilly, T., "Government as a Platform", Innovations: Technology, Governance, Globalization 6(1), 2011, pp. 1340.

[22] Otjacques, B., P. Hitzelberger, and F. Feltz, "Interoperability of E-Government Information Systems: Issues of Identification and Data Sharing", Journal of Management Information Systems 23(4), 2007, pp. 29-51.

[23] Scharpf, F.W., "The Joint-Decision Trap: Lessons from German Federalism and European Intergration", Public
Administration 66(3), 1988, pp. 239-278.

[24] Scheer, A.-W., ARIS - Business Process Frameworks, Springer, Berlin, Heidelberg, 1999.

[25] Scheer, A.-W., and K. Schneider, "ARIS Architecture of Integrated Information Systems", In P. Bernus, K. Mertins and G.J. Schmidt, eds., Handbook on Architectures of Information Systems. Springer, Berlin, Heidelberg, 2006, 605-623.

[26] Scholl, H.J., and R. Klischewski, "E-Government Integration and Interoperability: Framing the Research Agenda", International Journal of Public Administration 30(8-9), 2007, pp. 889-920.

[27] Scholta, H., W. Mertens, A. Reeve, and M. Kowalkiewicz, "From One-Stop-Shop to No-Stop-Shop: An E-Government Stage Model", Proceedings of the 25th European Conference on Information Systems (ECIS 2017), (2017), 918-934.

[28] Seltsikas, P., and R.M. O'Keefe, "Expectations and outcomes in electronic identity management: the role of trust and public value", European Journal of Information Systems 19(1), 2010, pp. 93-103.

[29] Shim, S.S.Y., G. Bhalla, and V. Pendyala, "Federated identity management", Computer 38(12), 2005, pp. 120-122.

[30] Smith, D.B., "Federalism in the United States of America”, Duquesne Law Review 43(4), 2002, pp. 519-538.

[31] United Nations, "United Nations E-Government Survey 2018: Gearing E-Government to support transformation towards sustainable and resilient societies", 2018. https://publicadministration.un.org/egovkb/Portals/egovkb/D ocuments/un/2018-Survey/E-Government Survey 2018_FINAL for web.pdf

[32] Wallis, J., and F. Zhao, "e-Government Development and Government Effectiveness: A Reciprocal Relationship", International Journal of Public Administration 41(7), 2017, pp. 479-491.

[33] Wang, S., and H. Wang, "Shared services beyond sourcing the back offices: Organizational design", Human Systems Management 26(4), 2007, pp. 281-290.

[34] Watts, R.L., "Federalism, Federal Political Systems, and Federations", Annual Review of Political Science 1, 1998, pp. $117-137$

[35] Watts, R.L., "Origins of Cooperative and Competitive Federalism", In S.L. Greer, ed., Territory, Democracy and Justice. Palgrave Macmillan UK, London, 2006, 201-223.

[36] Wheare, K.C., Federal Government, Oxford University Press, Oxford, GB, 1946.

[37] Wimmer, M.A., "Integrated Service Modelling for Online One-stop Government", Electronic Markets 12(3), 2002, pp. 149-156.

[38] Wimmer, M.A., "A European perspective towards online one-stop government: the eGOV project", Electronic Commerce Research and Applications 1(1), 2002, pp. 92103.

[39] Wimmer, M.A., and E. Tambouris, "Online One-Stop Government: A working framework and requirements", Proceedings of the 17th IFIP World Computer Congress, (2002). 